\title{
RESILIENT COMMUNITIES: A VULNERABILTIY ASSESSMENT IS ONLY STEP ONE
}

\author{
Lesley C. Ewing, PE, Ph.D., California Coastal Commission, lewing@coastal.ca.gov \\ Phyllis Grifman, University of Southern California Sea Grant, grifman@usc.edu
}

\begin{abstract}
INTRODUCTION
Sea level is rising and climate scientists project a rapid increase in the rise in sea level resulting from current greenhouse gas emissions and latent buildup of atmospheric carbon dioxide. Coastal cities are rapidly coming to grips with the possibility that much of their critical facilities, infrastructure, housing and cultural and environmental assets will need to adapt to changing coastal conditions in the coming years and decades.
\end{abstract}

Increasing sea level will exacerbate most of the coastal hazards that already plague coastal communities - beach and bluff erosion, flooding, inundation, wave impacts, rising groundwater, saltwater intrusion and other water-related hazards.. Discussions of resilience can provide a framework to help coastal communities examine and evaluate options for minimizing the consequence of the risks. Broadly speaking, resilience covers both efforts to minimize the extent of damage to a coastal community that results from a hazard event and ways that the community responds to damages and restored community functions. As defined by the US Army Corps of Engineers (the Corps), resilience includes preparation, protection, recovery, and adaptation.

In California, coastal communities are in various stages of vulnerability assessment development and adaptation planning (For example, Regional AdaptLA, USC Sea Grant, 2015). Numerous tools and studies are being developed to assist with the planning efforts. However, few communities have enacted steps beyond planning. The Coastal Community Hazard Protection Resilience Index (CCHPR Index) is a tool that helps communities evaluate adaptation options in the context of their economic, environmental and social/cultural expectations for the coast. Since development of the CCHPR Index (Ewing 2015), it has been applied to several coastal communities.

\section{OPTIONS FOR COASTAL ADAPTATION}

Coastal communities have a long history of protecting from coastal hazards, through a variety of planning and engineering efforts. Land use planning, zoning and building codes can direct development away from the highest hazard areas and ensure that the structures that are in high hazard areas can withstand some identified level of flooding or wave impacts. Insurance provides a safety net for some economic losses when damage does occur. Engineered structures afford some level of overall resistance to impacts, while natural shore features help to buffer or lessen the level of impact.

In the past, communities have tended to stick with the protective systems that are already in place, and as weaknesses or insufficiencies are identified in the systems, the communities strengthen, heighten or expand the system that is already in use. The planning efforts associated with increased sea level rise and growing awareness concerning the changes and/or hazards associated with rising sea level have caused many communities to realize that 'more of the same' might not be a sustainable long-term option. This has caused some communities to examine hazard responses anew and to examine options that were not previously considered. This is especially true for nature-based protective options that can be multi-functional and can provide a level of selfadaption.

\section{CCHPR INDEX AS A BRIDGE TO ADAPTATION}

As communities move from a hazard response strategy of "more of the same" to a broader, more comprehensive approach, they are facing an often daunting array of options. The CCHPR Index provides a quantitative rating of the economic, environmental and social-cultural values of a large number of protective elements. As such, it can help communities evaluate the range of benefits that can resulting from different protection options. The Index covers a broad array of protective elements that are independent of specific vulnerabilities or community assets, and it can be applied at various scales.

\section{CASE STUDIES}

The CCHPR Index is a rapid assessment tool that can help communities examine their existing suite of protection features and compare that will possible adaptation scenarios. The Index has been developed for several communities and it demonstrates the special characteristics of each location. It can help communities realize the importance of their shorelines, the values coming to the community from the existing protective elements and how values can change with different protective actions. The presentation will cover the uses for the CCHPR Index and how communities can improve resilience and change the economic, environmental and socio-cultural values through carefully consideration of sea level rise adaptation options.

\section{REFERENCES}

Ewing (2015) Resilience from coastal protection. Phil. Trans. R. Soc. A 373: 20140383. http://dx.doi.org/10.1098/rsta.2014.0383

USC Sea Grant (2015) Regional AdaptLA: Coastal Impacts Planning for the Los Angeles Region http://dornsife.usc.edu/assets/sites/291/docs/AdaptLA Fina I Reports/AdaptLA Full Report Final Jan 2017.pdf

US Army Corps of Engineers, Civil Works Directorate (2013) Coastal Risk Reduction and Resilience. http://www.corpsclimate.us/docs/USACE Coastal Risk Re duction final CWTS 2013-3.pdf. 